\title{
Geography and Sentencing: Does Country of Citizenship Influence Sentence Longevity?
}

\author{
Gale lles* and Oladipupo V. Adegun
}

University of Tennessee-Chattanooga, USA

\begin{abstract}
Contentious debates on immigrants in the United States has led to growing interest in their treatment in the criminal justice system. Much of what is known, however, springs from research that treats immigrants as a homogeneous group. The lumping of all immigrants into one category potentially mask variances in sentencing based on national origins. The current study disaggregates federal sentencing data to explore whether length of sentence differs by the defendants' geographical region of citizenship. After controlling for a number of legal and extra-legal factors, sentences imposed upon Mexican citizens were found to be longer than sentences meted out to defendants who are citizens of other countries. Evidence suggesting that national origin has a stronger influence on sentence length than race/ethnicity and legal status was also detected. Implications of the findings and directions for future research are discussed.
\end{abstract}

Keywords: Immigrants, Country of origin, U.S. Federal Sentencing, Disparity.

\section{INTRODUCTION}

On June 16, 2015, then presidential candidate Donald Trump announced his bid for presidency by stating that,

"When Mexico sends its people, they're not sending their best. They're not sending you. They're not sending you. They're sending people that have lots of problems, and they're bringing those problems with us. They're bringing drugs. They're bringing crime. They're rapists. And some, I assume, are good" (Washington Post staff 2015).

President Trump's comment is striking for two reasons. First, studies on the nexus of immigration and crime have generally concluded that immigrants commit less crimes when compared to the U.S. born population (Hagan and Palloni, 1998; Hagan and Palloni 1999; Martinez and Lee, 2000; Hagan, Levi and Dinovitzer 2008; Katz, Fox, and White 2011; Wright and Benson 2011) and that the growth of the immigrant population may actually be responsible for reduced crime rates (Ousey and Kubrin 2009; Wadsworth 2010). Within that context, we argue that his comment is misleading and may needlessly perpetuate negative stereotypes of immigrants as dangerous, threatening and crime prone. Second, it is important to note that President Trump's current wife (Melania Trump) and a former wife (Ivana Marie Zelnickova) are themselves immigrants (Solvenia and Czechoslovakia,

*Address correspondence to this author at the University of TennesseeChattanooga, USA; Tel: 423-425-2241; Fax: 423-425-2228;

E-mail: Gale-iles@utc.edu respectively). This observation leads us to believe that expressed fears and anxieties of immigrants are not consistent across all immigrant groups. Specifically, we argue that the singling out of Mexicans highlights assumed stereotypical distinctions between, for instance, immigrants from European countries versus immigrants from South American countries or even immigrants from Cuba versus immigrants from Haiti. Yet, much of what we know about non-U.S. citizens and their treatment in the criminal justice system stems from studies that lumps all immigrants into one group. The traditional practice of limiting analysis to the dichotomous U.S. citizen versus non-U.S. citizen (in essence aggregating all citizens from other countries into a single "non-U.S. citizen" category) is problematic as it may theoretically mask important differences between immigrant groups. The current study is an attempt to unmask those potential variances and at the same time build upon previous research on sentencing outcomes of immigrants. It does so by disaggregating the non-U.S. citizen category to assess whether a defendant's country of citizenship matter with respect to sentencing outcome. Our specific research question is, "Is the length of sentence for non-U.S. citizens convicted of drug trafficking influenced by the geographical region of the offender's country of citizenship?"

\section{LITERATURE REVIEW}

Despite sentencing reforms and laws targeted at producing equitable treatment, scholarly responsiveness to the matter continues to find unwarranted disparities based on a number of extralegal factors. Although much of the attention has focused on disparities predicated on race/ethnicity, 
results from an increasing number of studies are suggesting an even greater need to investigate the influence of citizenship status (Logue 2009; Demuth 2002; Hartley and Armendariz 2011; Wolfe, Pyrooz and Spohn 2011; Light 2014). In fact, Light (2014) found that not only were noncitizens treated more harshly at sentencing but she also found that disparity between citizens and noncitizens at punishment was larger than the disparity between white and minority offenders. The extant literature on the influence of citizenship are inconclusive or at best mixed. While some studies found no evidence of an influence of citizenship on sentence outcomes (Everett and Wojkiewicz 2002; Feldmeyer et al. 2015) the results of others (Wolfe et al. 2011; Light 2014; Wu and D'Angelo 2014) detect sentencing variation grounded on the citizenship status of the defendant. A smaller, but growing body of sentencing research (lles 2009; Logue 2009; Orrick and Piquero 2015) has gone beyond citizenship status to explore the effects of national origins. Iles (2009), for example, disaggregated the legal alien category in her study into four groups (South Americans/Mexican immigrants; Dominican Republic; Caribbean nations; and all other countries. With U.S. citizens serving as the reference group, she found that citizens of the Dominican Republic were awarded sentences that were 29.7 percent longer than the sentences imposed upon U.S. citizens (there were no differences among the other legal alien groups).

Logue's (2009) study is more streamlined in that she focused exclusively on non-citizen Mexican and non-Mexican Latinos convicted of drug trafficking. Partitioning the data by documented and undocumented immigrants, she not only found statistically significant effects based on immigration status but she also found support denoting that within each immigration status, aggravating and mitigating effects operated differently depending upon the national origin of the defendant. For example, her examination of differences between legal and illegal defendants by national origin revealed that being an undocumented immigrant has a more adverse impact on Mexicans relative to non-Mexican Latinos; being an illegal Mexican result in longer sentences while their non-Mexican Latino counterparts receive shorter sentences. Like Logue (2009), Orrick and Piquero (2015) also focused on Mexican nativity. They differentiated between three groups of defendants (Mexican born, other foreign-born defendants and U.S. citizen as the comparison group). Although the identified differences were small, their findings revealed that compared with other immigrants and U.S. citizens, defendants born in Mexico were recipients of more lenient sentence; Mexicans had a $16 \%$ decrease in expected sentence length.

Based on our review of the literature we are responding to what we consider a need to dig deeper into the effects of national origins. Our hope is to expand previous work by disaggregating measures of citizenship to investigate the effects of defendant's geographical region of citizenship. Similar to earlier studies, we focus solely on non-U.S. citizens. However, unlike lles (2009) who confined the illegal immigrants in her study to four groups or Logue (2009) who fixated on Mexican versus non-Mexican Latinos, we take a more pointed approach by classifying the wide array of defendant's country of citizenship into geographical regions of the world. We begin by briefly discussing a conceptual framework that we believe is relevant for studying the effects of national origins on the sentencing length of immigrants.

\section{CONCEPTUAL FRAMEWORK}

Sentencing scholars have long relied on the focal concern perspective to explain the sentencing decision making processes of judges, specifically the sources of unwarranted disparities (Steffensmeier, Ulmer, and Kramer, 1998; Steffensmeier and Demuth 2000; Kramer and Ulmer 2002; Hartley, Maddan, and Spohn 2007; Freiburger 2009; Iles 2009 and Wolfe et al. 2011). The cornerstone of this perspective is that judge's sentencing decisions are based on three focal concerns. First judges' decisions are believed to take into consideration the blameworthiness of the defendant and the degree of harm suffered by the victim. Second, judges' decisions are based on the need to protect the community from the perceived dangerous offender. Lastly, it is believed that judges also consider the practical/organizational constraints and consequences of the sentencing decision. For this concern, factors such as jail over-crowding and social costs (e.g., disruption of ties to children and family members) are taken into consideration. With these concerns at the forefront, there is an expectation that judges will make decisions based on well-calculated and rationally based factors. The reality, however, is that judges are not always equipped with sufficient time nor do they possess complete knowledge surrounding a particular case or defendant. Rather, they encounter an uncertain decision-making environment and therefore must engage in uncertainty management (Albonetti 1991; Johnson, Ulmer, and Kramer 1998). 
Faced with these limitations judges develop a "perceptual shorthand" to make bounded decisions regarding the culpability of the offender, how dangerous they are and their subsequent risk of recidivism. This perceptual-shorthand, in turn, is said to be based on and/or influenced by stereotypes and physical attributes of the offender.

Using the focal concern perspective as a backdrop, Light (2014) presents three arguments that makes the perspective relevant to the sentencing of noncitizens. First, she argues that since alternative sanctions such as drug rehabilitation and treatment are not available to non-citizens, judges have little option but to sentence non-citizens to incarceration or to detain them while deportation proceedings are underway. Second, and with regards to concerns over the culpability and dangerousness aspect of the focal concern perspective, Light (2014) argues that the conceptualization of citizenship as a gauge of one's location within the social structure of society will cause non-U.S. citizens to be viewed as possessing a higher propensity to commit crime and thus more deserving of harsher punishment. Lastly, she argues that residents who find themselves outside the "national community" or those considered "culturally dissimilar" are more likely to be perceived as blameworthy and in turn will be more likely to suffer the brunt of severe sanctions. Building upon Light's (2014) assertions, we contend that national origin too is germane to the focal concerns perspective. We argue that in addition to citizenship status, judges' consideration of defendants' country of citizenship may be used as a perceptual shorthand for determining the blameworthiness of the offender as well as their likelihood to recidivate. In the case of United States v. Borrero-Isaza (1989), for example, the sentencing judge noted that,

I just finished a case with two Colombian aliens. Not only aliens, illegal aliens ... People, such as Mr. Borrero are emboldened to undertake this type of crime because they don't think they are going to pay for it that much... It has gone too far ... that an illegal alien who doesn't speak the language from Colombia come here, and with impunity ... sell kilogram quantities of cocaine ... And somehow the people who are selling narcotics, particularly from source countries have to know that we in the Unites States mean business, and we are going to put a stop to this.
It appears that the judge went beyond Mr. BorreoIsaza's citizenship status as an alien to tailor his sentencing decision to the defendant's national origin. Specifically, calling attention to the defendant's country of citizenship (Colombia) and using it as a perceptual shorthand for drug dealers suggest that a German, for instance, would not be subject to the same penalty as a Colombian because Germany is not recognized as a source country for drugs.

Another example of an alleged association between national origin and crime propensity can be found in President Trump's third travel ban, which place travel restrictions on citizens from eight countries: Chad, Iran, Libya, North Korea, Somalia, Syria, Venezuela and Yemen. Although the ban is professed to be "based on express findings of inadequacies in the information sharing practices, identity-management protocols, and risk factors of certain countries" (de Vogue 2017:2), one can speculate that immigrants from the banned countries may instinctively be stereotyped as threatening and dangerous. As a result, any infraction carried out by immigrants from these countries may be met with unyielding penalizations. In short, if judges do share public perceptions that immigrants from particular countries have greater predisposition to commit certain types of crime than do other immigrants, there is the likelihood that a defendant's country of citizenship may become a proxy for dangerousness, thus potentially creating unwarranted sentencing disparities based on national origins. Due to lack of adequate information, for example, a judge may rely on stereotypes of Muslims as terrorist to predict the threat of a defendant from a Middle-Eastern country, Toward that end, we go beyond the typical examination of citizenship status to examine the influence of defendant's country of citizenship on sentencing outcomes.

\section{DATA AND METHOD}

Data for this study were drawn from the 2008 United States Sentencing Commission's (USSC) Monitoring of Federal Sentencing data series. In 2008 a total of 76,478 federal defendants were adjudicated in the United States. The population was reduced to 27,620 after the selection of only those cases involving nonU.S. citizens. Since the effects of extra-legal factors appears to be more pronounced in drug-related cases (Feldmeyer et al. 2015) we limited our study to drugtrafficking. The elimination of non-drug trafficking cases abridged our dataset to 6,947 cases. The sentencing of defendants involves a two-stage decision-making 
process. The first decision is whether or not to sentence the defendant to prison with the second decision being the length of sentence. However, as 98.9 percent of the defendants in our study received a prison sentence, we focused solely on sentence length. Doing so reduced our population to 6,873 , which was further reduced to a final sample size of 6,839 after the elimination of cases with missing values for sentence length and the exclusion of the two cases that represented the Oceana region (more on the elimination of these two cases later).

Our dependent variable is length of sentence. This outcome variable is measured in months and is capped at 470 , which according to the Sentencing Commission is a life sentence. The variable was further altered when we perform a logarithm transformation to account for skewness and to generate a more normal distribution. Our first group of independent variables represent the attributes of the offender. This includes the race/ethnicity of the defendant (white, black, Hispanic, and other races), gender dummy coded "0" for male and "1" for female, age measured as a continuous variable and educational attainment (less than high school, high school graduate, some college/college graduate). As you may recall, a focal concern of judges is the disruption of ties to children or families a sentencing decision may cause. For that reason, the number of dependents is also included as a control. Given that our principal focus are immigrants, we also added controls for legal status (resident/legal aliens, illegal aliens and unknown alien). The major contribution of this study is its examination of the effects of country of citizenship. As it is not feasible to control for every country in the sample, the decision was made to group defendants country of citizenship into geographical regions. Our nine geographical regions are Africa, Asia, Canada, Caribbean, Europe, Middle-east/North Africa, Mexico, South/Central America and Oceania. The nine regions were ultimately reduced to eight when the Oceania region (that includes Australia and New Zealand) was dropped as there were only two cases that fell within that region. The second group of predictors represent characteristics of the case. These dichotomous indicators include the defendant's pretrial detention status (bail "0" and in custody "1") and the mode of disposition (plea "0" and trial "1"). The last group of independent variables consist of legally relevant factors. The most crucial is the presumptive sentence which takes into consideration the severity of the offense. Also among this group of factors are the number of counts of convictions (a continuous variable) and whether or not the defendant has a prior criminal history (no $=0$, yes $=1$ ). To capture potential variation in sentencing departures, guideline departures are categorized as no departures, government sponsored downward departures (this includes substantial assistance), downward departures, and upward departures. Considering our focus on drug trafficking offenses, we also differentiated by drug type (cocaine, crack, heroin, marijuana, methamphetamine, and other drugs).

Multivariate analysis is performed using ordinary least squares (OLS). Since geographical regions of citizenship are our primary variable of interest, our first model examined the relationship between length of sentence and region absent controls for legally relevant factors and other predictors. To determine how the inclusion of legal and extra-legal factors affect regional coefficients, our second model introduced the confounding variables. As almost 73 percent of the cases involved defendants from the Mexican region, we created a third model, which dichotomizes the regional variables to compare the Mexican region to all other regions.

Despite the major contributions that can materialize from the current study, there are two primary limitations. First the study is limited in the sense that its findings cannot be generalized to other offenses. Our study focuses on the influence of country of citizenship on drug offenders. Drug offenses is an important distinction because as Martinez and Lee $(2000)$ have correctly pointed out, scholars (Lind 1930; Sellin 1938; Sutherland 1947; Sutherland and Cressey 1960) have established that certain types of crimes are more likely to be carried out by a specific immigrant group. Therefore, it is possible that the results of our study would be different if other offenses were included. A second limitation is our focus on federal cases. Defendants convicted in state courts may face altogether different outcomes. The possibility of deportation for state defendants, for example, may not be equal to that of federal defendants; defendants sentenced on the state level may receive longer sentences compared to their federal counterparts who face the likelihood of deportation, and thus may be awarded shorter sentences.

\section{FINDINGS}

Table 1 displays the descriptive statistics. The average length of sentence is 63 months. The typical defendant is Hispanic (83.2 percent), male (92.3 
Table 1: Descriptive Statistics for Dependent and Independent Variables

\begin{tabular}{|c|c|c|c|c|}
\hline Variable & $\mathbf{N}$ & $\%$ & Mean & SD \\
\hline \multicolumn{5}{|l|}{ Dependent Variable } \\
\hline \multicolumn{5}{|l|}{ Independent Variables } \\
\hline \multicolumn{5}{|l|}{ Extra-Legal Factors } \\
\hline Whites & 652 & 9.6 & & \\
\hline Blacks & 309 & 4.5 & & \\
\hline${ }^{*}$ Hispanics & 5679 & 83.2 & & \\
\hline Other & 184 & 2.7 & & \\
\hline Age & & & 33.70 & 10.1 \\
\hline $\mathrm{Age}^{2}$ & & & 1239.1 & 779.23 \\
\hline \multicolumn{5}{|l|}{ Education } \\
\hline *Less than HS & 4627 & 69.2 & & \\
\hline H.S Grad & 1185 & 17.7 & & \\
\hline Some College & 647 & 9.7 & & \\
\hline College Grad & 226 & 3.4 & & \\
\hline Number of Dependents & & & 1.93 & 1.81 \\
\hline Asia & 166 & 2.4 & & \\
\hline Canada & 117 & 1.7 & & \\
\hline Caribbean & 747 & 10.9 & & \\
\hline Europe & 56 & 0.8 & & \\
\hline Middle East/N. Africa & 29 & 0.4 & & \\
\hline *Mexico & 4980 & 72.8 & & \\
\hline South/Central America & 659 & 9.6 & & \\
\hline \multicolumn{5}{|c|}{ Mid-range Extra Legal Factors (Case Processing) } \\
\hline \multicolumn{5}{|l|}{ Pretrial Dent. Status } \\
\hline Bail & 360 & 5.3 & & \\
\hline *In Custody & 6465 & 94.7 & & \\
\hline \multicolumn{5}{|l|}{ Mode of Disposition } \\
\hline Plea & 6589 & 96.3 & & \\
\hline *Trial & 250 & 3.7 & & \\
\hline
\end{tabular}


(Table 1). Continued

\begin{tabular}{|c|c|c|c|c|}
\hline \multicolumn{5}{|l|}{ Legally Relevant Factors } \\
\hline \multicolumn{5}{|l|}{ Criminal History } \\
\hline No & 3565 & 52.2 & & \\
\hline \multicolumn{5}{|l|}{ Departures } \\
\hline *Within Range & 3731 & 54.8 & & \\
\hline Above Range & 25 & 0.4 & & \\
\hline Govt. Sponsored & 2236 & 32.8 & & \\
\hline Crack & 196 & 2.9 & & \\
\hline Heroin & 576 & 8.4 & & \\
\hline *Marijuana & 2655 & 38.9 & & \\
\hline Methamphetamine & 1161 & 17.0 & & \\
\hline Other & 182 & 2.7 & & \\
\hline Sentence & & & 63.39 & 61.68 \\
\hline
\end{tabular}

$N=6,839$.

ABBREVIATION: SD= Standard Deviation.

${ }^{*}=$ Reference Category.

percent), 34 years of age, have less than a high school education (69.2 percent), and on average have 1.9 dependents. In terms of citizenship status, slightly over a quarter (27.2 percent) of defendants are resident/legal aliens with the vast majority $(65.3$ percent) classified as illegal aliens. Turning now to our main variable of interest, an overwhelming 72.8 percent of defendants are Mexican nationals. The next largest group of defendants are from the Caribbean (10.9 percent), followed by South/Central America (9.6 percent), Asia (2.4 percent), Canada (1.7 percent), Africa (1.2 percent), Europe (0.8 percent) and the Middle East/North Africa (0.4 percent). Case processing variables discloses that almost 95 percent of defendants are held in custody prior to sentencing and an almost equal percentage of cases (96.3 percent) are disposed via plea agreements. As to legally relevant factors, the average number of counts of conviction is 1.31 and defendants are almost evenly divided with respect to their criminal histories; 52.2 percent have no prior records while 47.8 percent have a prior record. More than half of the defendants (54.8 percent) are sentenced within the sentencing range, 44.8 receive a downward departure (32.8 government sponsored; 12 percent other downward departures) and the remaining 0.4 percent of defendants receive an upward departure. The typical drug offense is marijuana (38.9 percent), followed by cocaine (30.0 percent), methamphetamine (17.0 percent), heroine (8.4 percent), crack (2.9 percent) then other drugs (2.7 percent).

Table 2 presents cross-tabulations of offender, case, and legally-relevant factors by region. As expected, the largest percentages of black defendants journeyed from the African (89.4 percent) and Caribbean (25.3 percent) regions while the greatest percentages of Hispanics migrated from South/Central America (92.7) and Mexico (90.8). White defendants are predominately from the Middle-East/North Africa (79.3 percent), Europe (66.1 percent) and Canada (63.5 percent). With regards to gender, all 29 defendants from the Middle East/North Africa are males. With the exception of the Canadian region, which has the highest percentage of females (13.7 percent), males constituted over 90 percent of defendants in the regions. The most educated offenders, those with a college degree, are from the African region (18.1 percent) whereas the least educated offenders, those with less than a high school education, are Mexican nationals (76.9 percent). 
Table 2: Characteristics by Regions

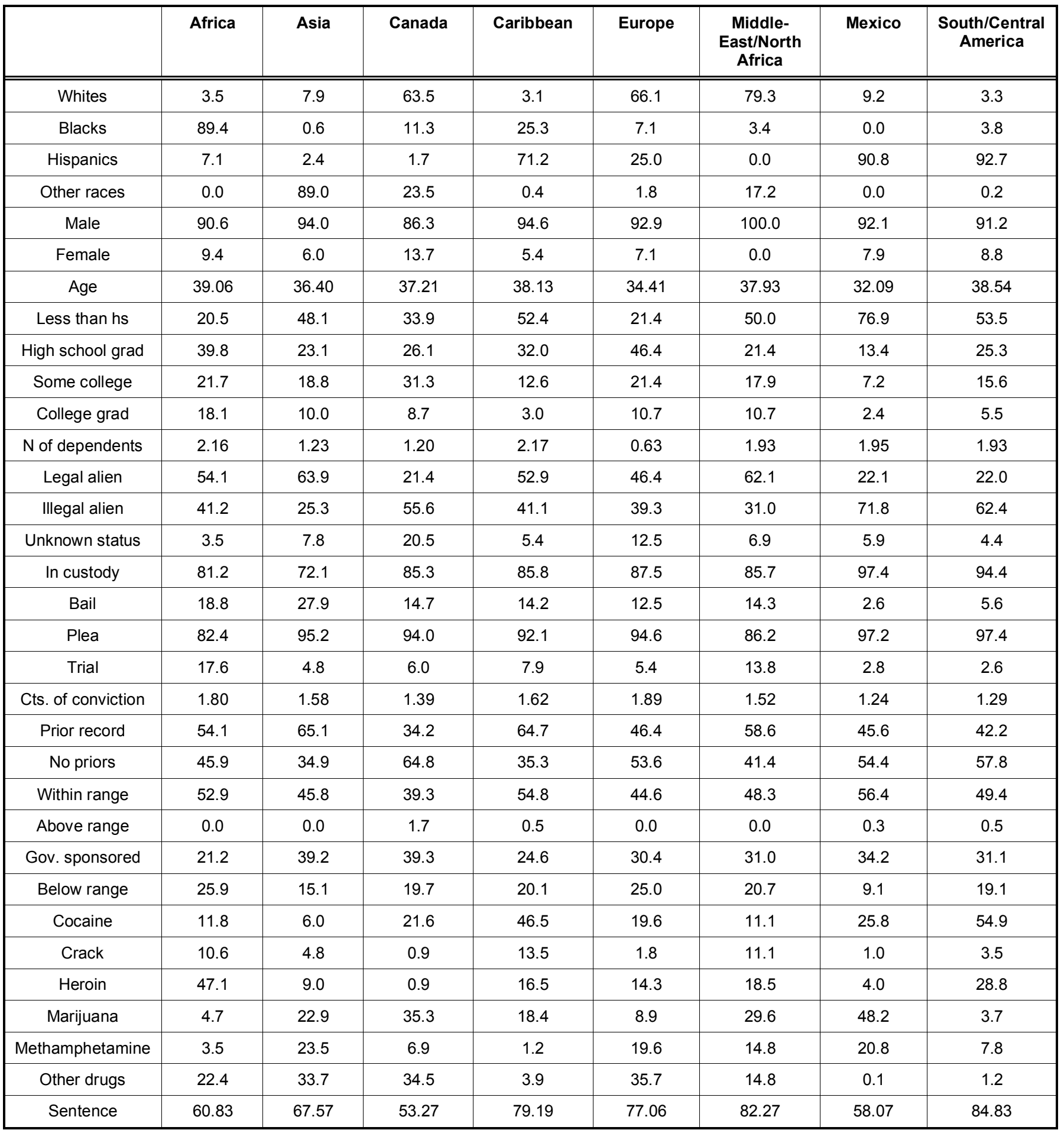

Note: All numbers represent percentages.

Defendants in the Caribbean and Africa have more dependents than defendants in other regions, 2.17 and 2.16 respectively. Both Mexico (71 percent) and South/Central America (64.2 percent) have the largest percentage of illegal aliens. Conversely, the regions with the highest percentage of legal aliens are Asia (63.9 percent) and the Middle/East-North Africa (62.1 percent). Considering that a large percentage of Mexicans and South/Central Americans are illegal aliens, it is not surprising that defendants from those two regions (Mexico - 97.4 percent and South/Central America - 94.4 percent) are considerably more likely than defendants from other regions to be held in custody and also more likely to plead guilty (Mexico - 
Table 3: OLS Regression Models for Length of Sentence

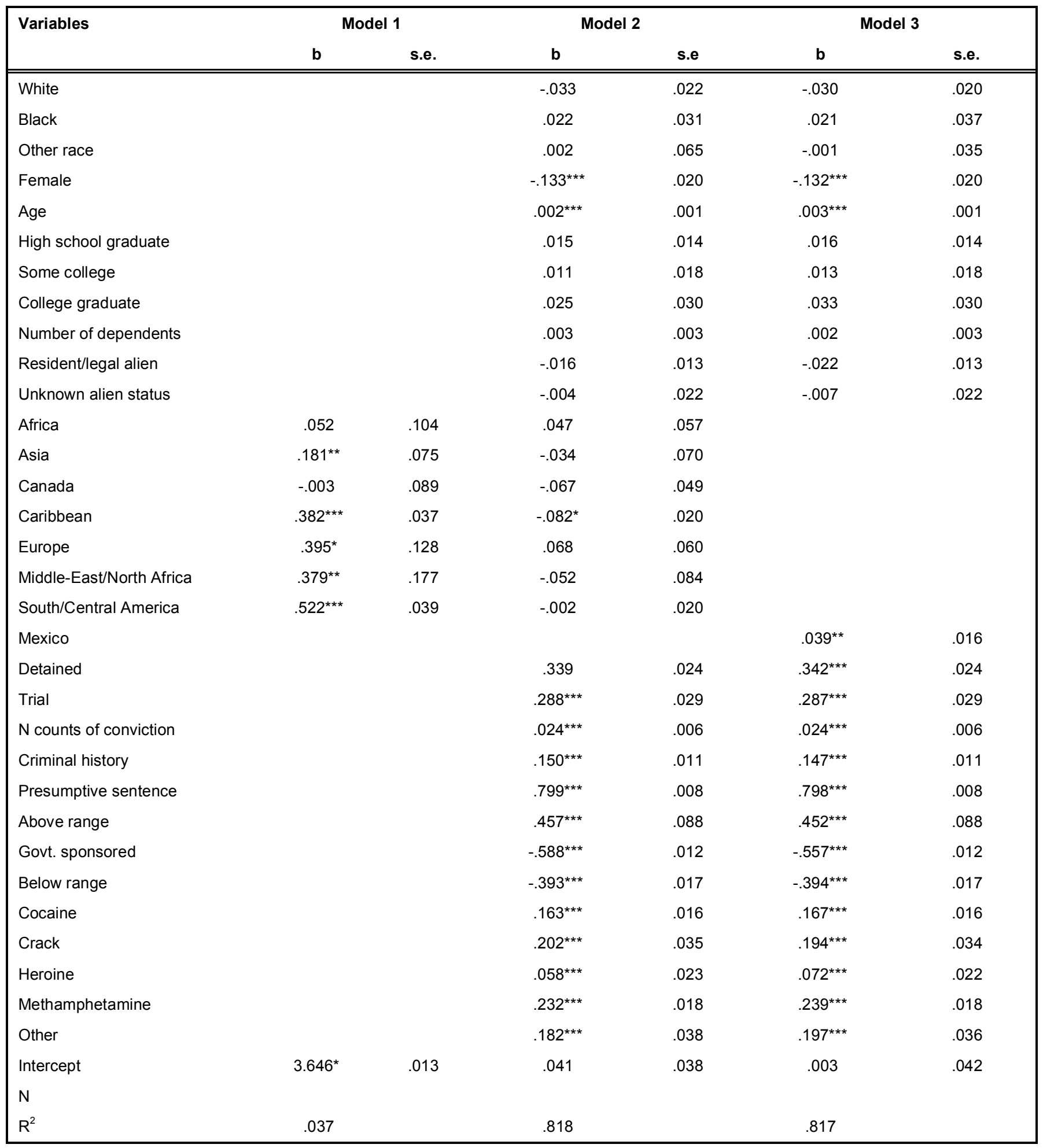

${ }^{*} p<.05 .{ }^{* *} p<.01 .{ }^{*} p<.001$.

97.2 percent; South/Central America - 97.4 percent). While the number of counts of convictions are fairly consistent across the regions, the table shows that defendants from Asia (65.1 percent) and the Caribbean (64.7 percent) are more likely to have a prior record whereas defendants from Canada (34.2 percent) are least likely to have a criminal history. More than half of defendants from Mexico (56.4 percent), the Caribbean (54.8 percent) and Africa (52.9 percent) are sentenced within the guidelines. However, while defendants in the 
African (25.9 percent) and European (25 percent) regions are more likely than other defendants to receive sentences below the range, they are less likely to receive government sponsored departures. While Table 1, displayed an average length of sentence of 63.3 months, the equivalent of 5.2 years, Table 2 shows that defendants from South/Central America are serving sentences that are two years longer than the average. Offenders from the Middle East/North African region trails with an average sentence of 6.83 years. Meanwhile, the shortest sentences are granted to defendants from the Canadian region (4.43 years) and defendants from the Mexican region (4.89 years).

Presented in Table 3 are the results of the regression models. Model 1 reports the findings of the effects of geographical region on sentence length absent controls for extra-legal and legally relevant measures. Statistically significant differences in length of sentence by geographical regions are detected and shows that defendants from Asia, Caribbean, Europe, the Middle East/North Africa and South America are subject to sentences that are 19.8, 46.5, 48.4, 46.0, 68.5 percent longer than sentences imposed on defendants from the Mexican region. Model 2 adds the remaining variables to the equation. Consistent with prior research, the legally proscribed factors emerge as the strongest predictor of sentence length with the presumptive sentence leading the way as the most influential factor. Among extra-legal factors, only gender and age surface as statistically significant with gender $(b=-.133)$ materializing as the most influential predictor on length of sentence among extra-legal variables. Noteworthy is the observation that being a citizen of a country in the Caribbean region is the second strongest predictor of sentence outcome. The statistically significant b-coefficient shows that offenders from countries in the Caribbean receive sentences that are 7.8 percent shorter than sentences imposed on Mexican nationals. Although coefficients for the remaining regions are statistically insignificant, it is worth mentioning that with the exception of defendants from South/Central America, the high bcoefficients for the geographical regions suggest that national origin has more influence on sentence longevity than race/ethnicity, age, education, number of dependents and citizenship status.

Model 3 compares the Mexican region to all other regions. As observed in the second model, the third model also uncovers statistically significant effects of national origins; offenders from the Mexican region receive sentences that are 3.9 percent longer than sentences imposed on defendants from other geographical regions. In addition, like Model 2, the effects of national origins in Model 3 was again found to exhibit the second strongest influence on the length of sentence among extra-legal factors; gender being the most influential.

\section{DISCUSSION AND CONCLUSION}

Does sentence length vary according to a defendant's geographical region of citizenship? According to the results of the current study the answer is yes. Consistent with prior research, we detected evidence that national origin does have an influence on length of sentence. Our first model disclosed that absent controls, the coefficients for five of the seven geographical regions are statistically significant and shows that defendants from Mexico receive sentences that are more lenient than sentences imposed on defendants from Asia, the Caribbean, Europe, Middle East/North Africa and South/Central America. When extra-legal and legally-relevant factors were added in Model 2, a statistically significant association between defendants from the Caribbean region and sentence length remained. However, the results are reversed in that Mexicans are now the recipients of harsher sentences. Our third model, which compared the Mexican region to all other regions, also found evidence of the influence of national origins with Mexicans again receiving longer sentences.

Based on our findings, two general statements can be made. First, the more severe penalties imposed on Mexicans is not unexpected. As you may recall, then presidential candidate Donald Trump announced his candidacy by stating that, Mexico are not sending their best, but rather are sending people with "lots of problems" (Washington Post 2016:2) and are bringing with them drugs and crime. Such disparagements of Mexicans may have negative consequences when it comes to sentencing. Judges sentencing decision, for instance, are not constructed in a vacuum. As members of the community, judges may rely on prevalent stereotypes and prejudices that exists within that community to fashion their sentencing decision. Consistent with the focal concern perspective, if judges do share public perceptions of Mexicans as a "problem population" they may use Mexican origin as a proxy for dangerousness and their actions will accordingly lead to the harsher sentences of Mexican defendants.

Second, Light (2014) concluded that for both the in/out decision and length of sentence, unwarranted 
sentencing disparities were larger between citizens and noncitizens than between blacks and whites. This insinuates that citizenship status is a bigger predictor of sentence outcome than race/ethnicity. Similarly, the statistically significant b-coefficient for measures of geographical regions of citizenships in our study emerged as having more influence on the length of sentence than not just race/ethnicity but also citizenship status (legal immigrants versus illegal immigrants). In fact, with the exception of gender, the coefficients for measures of country of citizenship were larger than the coefficients for the other extra-legal factors. This observation on the strength of national origin buttress our cries to go beyond the traditional exploration of the effects of race/ethnicity and citizenship status to explore the influence of national origin.

In closing, the identification of disparity based on geographical region of citizenship is notable because although the federal sentencing guideline is no longer mandatory, but rather advisory, provision $5 \mathrm{H} 1.10$ nonetheless precludes judges from tailoring sentences based on personal attributes of the offender. To be clear, the provision specifically stipulates that national origin, among other extra-legal factors are "not relevant in the determination of a sentence" (U.S. Sentencing Commission, 2016). Yet, we found that geographical region of citizenship status does matter with respect to sentence longevity. More emphatically, our results confirm that national origins carry more weight than race/ethnicity and citizenship status in explaining unwarranted sentencing disparities. The implication of the findings is that policies or programs that treats all immigrants as a homogeneous group can conceal meaningful differences between immigrants. Fortunately, federal sentencing data does include information on defendant's country of origin. In light of our findings we encourage future research to consider disentangling the data to allow for the examination of potentially hidden differences in sentencing outcomes within the various subgroups of immigrants. Only by doing so can we truly capture how diverse immigrant groups fare in our system of justice.

\section{REFERENCES}

Albonetti, Celesta A. 1991. "An Integration of Theories to Explain Judicial Discretion." Social Problems 38(2):247-266. https://doi.org/10.2307/800532

de Vogue, Ariane. 2017. Challengers Back at Supreme Court Hoping to Block Latest Travel Ban. CNN. Retrieved November 28, 2017. (http://www.cnn.com/2017/11/28/politics/travel-bansupreme-court/index.html)
Demuth, Stephen. 2002. "The Effect of Citizenship Status on Sentencing Outcomes in Drug Cases." Federal Sentencing Reporter 14(5):271-275. https://doi.org/10.1525/fsr.2002.14.5.271

Everett, Ronald. S. and Roger A. Wojtkiewicz. 2002. "Difference, Disparity, and Race/Ethnic Bias in Federal Sentencing." Journal of Quantitative Criminology 18(2):189-211. https://doi.org/10.1023/A:1015258732676

Feldmeyer, B., Patricia Y. Warren, Sonja E. Siennick, and Malisa Neptune. 2015. "Racial, Ethnic, and Immigrant Threat: Is There a New Criminal Threat on State Sentencing?" Journal of Research in Crime and Delinquency 52(1):62-92. https://doi.org/10.1177/0022427814548488

Freiburger, Tina. L. 2009. "Race and the Sentencing of Drug Offenders: An Examination of the Focal Concerns Perspective." Southwest Journal of Criminal Justice 6(2) 163177.

Hagan, John and Alberto Palloni. 1998. "Immigration and crime in the United States." Pp. 367-387 in The Immigration Debate: Studies on the Economic, Demographic, and Fiscal Effects of Immigration edited by J. P. Smith and B. Edmonston. Washington, D.C: National Academy Press.

Hagan, John and Alberto Palloni. 1999. "Sociological Criminology and the Mythology of Hispanic Immigration and Crime." Social Problems 617-632. https://doi.org/10.2307/3097078

Hagan, John, Ron Levi and, Ronit Dinovitzer. 2008. "The Symbolic Violence of the Crime-Immigration Nexus: Migrant Mythologies in the Americas." Criminology \& Public Policy 7(1):95-112.

https://doi.org/10.1111/j.1745-9133.2008.00493.x

Hartley, Richard D. and Louisa F. Armendariz. 2011. "Border justice? Sentencing Federal Narcotics Offenders in Southwest Border Districts: A Focus on Citizenship Status." Journal of Contemporary Criminal Justice 27(1):43-62. https://doi.org/10.1177/1043986211402208

Hartley, Richard D., Sean Maddan, and Cassia C. Spohn. 2007. "Prosecutorial Discretion: An Examination of Substantial Assistance Departures in Federal Crack-Cocaine and Powder-Cocaine Cases." Justice Quarterly 24(3):382-407. https://doi.org/10.1080/07418820701485379

Iles, Gale. 2009. "The Effects of Race /Ethnicity and National Origin on Length of Sentence in the United States Virgin Islands." The Annals of the American Academy of Political and Social Science 623(1):64-76. https://doi.org/10.1177/0002716208330705

Johnson, Brian D., Jeffery T. Ulmer and John H. Kramer. 1998. "The Social Context of Guidelines Circumvention: The Case of Federal District Courts." Criminology 46(3):737- 783. https://doi.org/10.1111/j.1745-9125.2008.00125.x

Katz, Charles M., Andrew M. Fox, and Michael D. White. 2011 "Assessing the relationship between immigration status and drug use." Justice Quarterly 28(4):541-575. https://doi.org/10.1080/07418825.2010.514277

Kramer, John K. and Jeffery T. Ulmer. 2002. "Downward Departures for Serious Violent Offenders: Local Court "Corrections" to Pennsylvania's Sentencing Guidelines." Criminology 40(4):897-932. https://doi.org/10.1111/j.1745-9125.2002.tb00977.x

Light, Michael. T. 2014. "The New Face of Legal Inequality: Noncitizens and the Long-Term Trends in Sentencing Disparities across US District Courts, 1992-2009." Law \& Society Review 48(2):447-478. https://doi.org/10.1111/lasr.12073

Lind, A. 1930. "Some Ecological Patterns of Community Disorganization in Honolulu." American Journal of Sociology 36(2):206-220. https://doi.org/10.1086/215337 
Logue, M. A. 2009. "The price of being Mexican: Sentencing disparities between noncitizen Mexican and non-Mexican Latinos in the federal courts." Hispanic Journal of Behavioral Sciences 31(4):423-445. https://doi.org/10.1177/0739986309347447

Martinez Jr, Ramiro and Matthew T. Lee. 2000. "On Immigration and Crime." Criminal Justice 1(1):486-524.

Orrick, Eric A. and Alex R. Piquero. 2015. "Assessing the impact of Mexican nativity on sentence length." Criminal Justice Policy Review 26(7):643-664. https://doi.org/10.1177/0887403414528949

Ousey, Graham C. and Charis E. Kubrin. 2009. "Exploring the connection between immigration and violent crime rates in U.S. cities. 1980-2000." Social Problems 56(3):447-473. https://doi.org/10.1525/sp.2009.56.3.447

Sellin, Thorsten. 1938. Culture Conflict and Crime. New York, NY: Social Science Research

Steffensmeier, Darrell and Stephen Demuth. 2000. "Ethnicity and Sentencing Outcomes in US Federal Courts: Who is Punished More Harshly?" American Sociological Review 705-729. https://doi.org/10.2307/2657543

Steffensmeier, Darrell, Jeffery Ulmer and John Kramer. 1998. "The Interaction of Race, Gender, and Age in Criminal Sentencing: The Punishment Cost of Being Young, Black, and Male." Criminology 36(4):763-798. https://doi.org/10.1111/j.1745-9125.1998.tb01265.x

Sutherland, Edwin. 1947. Principles of Criminology. $4^{\text {th }}$ ed. Chicago, IL: J.B. Lippincott.

Sutherland, Edwin and Donald Cressey. 1960. Principles of Criminology. $6^{\text {th }}$ ed. Chicago, IL: J.B. Lippincott.

U.S. Sentencing Commission. 2016. Guidelines Manual. Retrieved December 11, 2017 (https://www.ussc.gov/sites/ default/files/pdf/guidelines-manual/2016/CHAPTER_5.pdf).
Wadsworth, Tim. 2010. "Is immigration responsible for the crime drop? An assessment of the influence of immigration on changes in violent crime between 1990 and 2000." Social Science Quarterly 91(2):531-553. https://doi.org/10.1111/j.1540-6237.2010.00706.x

Washington post staff. 2015. Full text: Donald Trump Announces a Presidential bid. The Washington Post. Retrieved May 13, 2017 (https://www.washingtonpost.com/news/postpolitics/wp/2015/06/16/full-text-donald-trump-announces-apresidential-bid/?utm_term=.77be52e1d947).

Wolfe, Scott E., David C. Pyrooz and Cassia C. Spohn. 2011. "Unraveling the Effect of Offender Citizenship Status on Federal Sentencing Outcomes." Social Science Research 40(1):349-362. https://doi.org/10.1016/i.ssresearch.2010.09.013

Wright, Emily M. and Michael L. Benson. 2010. "Immigration and Intimate Partner Violence: Exploring the Immigrant Paradox." Social Problems 57:480-503. https://doi.org/10.1525/sp.2010.57.3.480

Wu, Jawjeong and Miriam A. DeLone. 2012. "Revisiting the Normal Crime and Liberation Hypothesis: Citizenship Status and Unwarranted Disparity." Criminal Justice Review 37(2):214238.

https://doi.org/10.1177/0734016811436336

Wu, Jawjeong and Jill M. D'Angelo. 2014. "Unwarranted Disparity in Federal Sentencing: Noncitizen Crime as a Social/Group Threat." Criminal Justice Review 39(58):58-80. https://doi.org/10.1177/0734016814522644

\section{Court Cases}

United States v. Borrero-Isaza, 887 F. 2d 1349 (1989).

Received on 28-12-2017

Accepted on 03-01-2018

Published on 02-02-2018

\section{DOI: https://doi.org/10.6000/1929-4409.2018.07.05}

(c) 2018 Iles and Adegun; Licensee Lifescience Global.

This is an open access article licensed under the terms of the Creative Commons Attribution Non-Commercial License (http://creativecommons.org/licenses/by-nc/3.0/) which permits unrestricted, non-commercial use, distribution and reproduction in any medium, provided the work is properly cited. 